\title{
Nanoscale
}

D) Check for updates

Cite this: Nanoscale, 2020, 12, 7782

\section{An anisotropic layer-by-layer carbon nanotube/boron nitride/rubber composite and its application in electromagnetic shielding $\dagger$}

\author{
Yanhu Zhan, (D) a Emanuele Lago, b,c Chiara Santillo, ${ }^{d}$ \\ Antonio Esaú Del Río Castillo, (DD ${ }^{b}$ Shuai Hao, ${ }^{e}$ Giovanna G. Buonocore, ${ }^{d}$ \\ Zhenming Chen, ${ }^{f}$ Hesheng Xia, (D) *e Marino Lavorgna (D)*d and \\ Francesco Bonaccorso (iD) b,g
}

\begin{abstract}
Multifunctional polymer composites with anisotropic properties are attracting interest as they fulfil the growing demand of multitasking materials. In this work, anisotropic polymer composites have been fabricated by combining the layer-by-layer (LBL) filtration method with the alternative assembling of carbon nanotubes (CNTs) and hexagonal boron nitride flakes (hBN) on natural rubber latex particles (NR). The layered composites exhibit anisotropic thermal and electrical conductivities, which are tailored through the layer formulations. The best composite consists of four layers of NR modified with $8 \mathrm{phr}$ (parts per Hundred Rubber) CNTs ( 7.4 wt\%) and four alternate layers with $12 \mathrm{phr} h \mathrm{hNN}(\sim 10.7 \mathrm{wt} \%)$. The composites exhibit an electromagnetic interference (EMI) shielding effectiveness of $22.41 \pm 0.14 \mathrm{~dB} \mathrm{~mm}^{-1}$ at 10.3 $\mathrm{GHz}$ and a thermal conductivity equal to $0.25 \mathrm{~W} \mathrm{~m}^{-1} \mathrm{~K}^{-1}$. Furthermore, when the layered composite is used as an electrical thermal heater the surface reaches a stable temperature of $\sim 103^{\circ} \mathrm{C}$ in approx. 2 min, with an input bias of $2.5 \mathrm{~V}$.
\end{abstract}

Received 18th December 2019, Accepted 15th March 2020

DOI: 10.1039/c9nr10672c

rsc.li/nanoscale made of electrically conductive magnetic materials, which act as a barrier towards the EM radiation. ${ }^{4,5}$ Usually, metallic materials e.g. magnesium- ${ }^{6}$ silver- ${ }^{7}$ and copper-based electronic packaging ${ }^{8}$ are used to protect sensitive electronic components by reflecting most of the incident radiation. Alternatively, conductive polymer composites (CPCs) are attracting attention due to their mechanical flexibility, light weight, corrosion resistance, and easy-processing at low cost. ${ }^{5}$ Of note, the EMI shielding effectiveness (EMI SE) of CPCs is mainly due to the EM wave absorption mechanism, which converts the incident electromagnetic energy into heat. ${ }^{9}$ The energy conversion depends on the electrical conductivity and the electrical and magnetic polarization losses of the material. ${ }^{9}$ The increase in temperature, due to energy conversion, might affect the functionality of the electronic components, reducing their lifetime. ${ }^{9}$ In this case, CPCs obtained by using electrically and thermally conductive fillers, i.e. carbon nanotubes (CNTs) ${ }^{10-14}$ graphene ${ }^{15-19}$ or reduced graphene oxide (RGO), ${ }^{20}$ and MXenes ${ }^{21-26}$ represent valuable solutions to introduce a shielding layer able to protect the device and dissipate the heat simultaneously. In this context, CNT- $\mathrm{Fe}_{3} \mathrm{O}_{4} @ \mathrm{Ag} /$ epoxy nanocomposites were designed, exhibiting an EMI SE and a thermal conductivity equal to $35 \mathrm{~dB}$ and $0.46 \mathrm{~W} \mathrm{~m}^{-1} \mathrm{~K}^{-1}$, respectively. ${ }^{27}$ Graphene-based materials have also been used, i.e., graphene/RGO foam/epoxy, for the realization of EMI 
shielding nanocomposites, obtaining values of EMI SE up to 51 $\mathrm{dB}$ with a thermal conductivity of $1.56 \mathrm{~W} \mathrm{~m}{ }^{-1} \mathrm{~K}^{-1} \cdot{ }^{28}$

Under specific conditions, i.e., significant overheat of electronic devices, it may be useful to use EMI shielding materials exhibiting both in-plane electrical conductivity and throughplane thermal conductivity. In this case, such an anisotropic material will stop the incident EM radiation and will provide the necessary thermal protection for electronic devices through heat dissipation. In this context, anisotropic CPCs with high through-plane thermal conductivity, high in-plane electrical conductivity and low through-plane electrical conductivity are suitable to meet the key specific requirements for the realisation of smart electronic packaging. Alongside carbonaceous conductive fillers (i.e. CNTs and graphene), hexagonal boron nitride $(h \mathrm{BN})$ filler, being an electrical insulating and thermally conductive material, has recently attracted great attention as a suitable candidate to construct anisotropic materials through the layer-by-layer (LBL) approach. ${ }^{29-31}$ In this regard, LBL (32 layers) polyethene/hBN/CNT/graphite composites displayed a thermal conductivity of $1.45 \mathrm{~W} \mathrm{~m}^{-1} \mathrm{~K}^{-1}$. $^{32}$ Similarly, a silicon rubber/graphene/ $h \mathrm{BN}$ composite (16 layers) exhibited a thermal conductivity of $1.25 \mathrm{~W} \mathrm{~m}^{-1} \mathrm{~K}^{-1}$, an electrical resistivity of $10^{12} \Omega \mathrm{cm}$ in the through-plane direction, and reached an EMI SE value of $40.67 \mathrm{~dB}$ with a filler content of $\sim 17.8$ vol\%. ${ }^{33}$ It is worth mentioning that the composites with good electrical conductivity along the in-plane direction and high thermal conductivity in the through-plane direction can be used as electrically driven heaters with potential use as defoggers or defroster devices. ${ }^{34}$ In these devices, laminated polymer/conductive filler/hBN composites can be heated by applying a bias voltage, removing ice and protecting the device at low temperatures operation. Simultaneously, the heat produced by the device is dissipated. ${ }^{35}$ However, the production of composites with an LBL structure requires a large amount of fillers to achieve the required combination of thermal conductivity, Joule effect and EMI shielding properties. ${ }^{36,37}$ Therefore, the design and preparation of composites with a more efficient LBL segregated filler network may represent a viable approach for reducing the filler content and improving both the thermal and electrical conductivity of layered structure polymer composites. ${ }^{36-39}$

In previous reports, the segregated carbonaceous filler network was constructed through a rubber-based latex mixing approach. ${ }^{4,20,36,39}$ In detail, the latex particles force the filler into the excluded-volume in between the particles forming a continuous network, thereby reducing the volume of filler necessary to achieve the electrical percolation (less than 0.62 vol\% as compared to $4.62 \mathrm{vol} \%$ when the filler is randomly dispersed). ${ }^{39,40}$ Besides the high-electrical and -thermal conductivity at the lowest concentration needed to reach the percolation threshold, the additional advantages of this method are the ease of mixing and its eco-sustainability due to the use of water as the solvent. Composites with a filler segregated network, such as $\mathrm{Fe}_{3} \mathrm{O}_{4} @ \mathrm{RGO} /$ rubber, ${ }^{20} \mathrm{CNT} / \mathrm{rubber},{ }^{41}$ $\mathrm{Fe}_{3} \mathrm{O}_{4} @$ @graphene/poly(methyl methacrylate), ${ }^{42}$ polystyrene/ $\mathrm{BN},{ }^{43}$ ultra-high-molecular-weight-polyethylene/BN, ${ }^{44}$ and polypropylene/graphite, ${ }^{45}$ were all prepared by filler self-assembling and the latex method for EMI shielding and thermally conductive applications.

Natural rubber latex obtained from Hevea brasiliensis tree is an environmentally friendly and low-cost material, which can be easily processed with well-established technologies. ${ }^{46}$ These advantages, combined with its excellent mechanical properties, make the natural rubber an ideal candidate to realize composites useful for many applications, e.g., tires, seals or shock absorptions. In this work, natural rubber-based composites exhibiting a layered structure have been prepared by combining the mixing and the vacuum-assisted filtration methods. Particularly, rubber-based layered composites with CNTs and $h \mathrm{BN}$ (RCB), obtained by alternating layers made of natural rubber (NR)/CNTs and NR/hBN exhibit high electrical conductivity $\left(1 \mathrm{~S} \mathrm{~cm}^{-1}\right)$ and high electrical insulation in the in-plane direction and thermal conductivity in the through-plane direction $\left(0.25 \mathrm{~W} \mathrm{~m}^{-1} \mathrm{~K}^{-1}\right)$. When EM waves enter into the composites from the NR/hBN layer, the EMI SE of the RCB composite with layers containing $h \mathrm{BN}$ at $16 \mathrm{phr}(\sim 13.8 \mathrm{wt} \%)$ and CNTs at $8 \mathrm{phr}(\sim 7.4 \mathrm{wt} \%)$, with a total thickness of $1.4 \mathrm{~mm}$, is $31.38 \pm$ $0.2 \mathrm{~dB}$. At the same time, the heat energy converted from EMI energy can be dissipated into the environment because of its high through-plane thermal conductivity $\left(0.25 \mathrm{~W} \mathrm{~m}^{-1} \mathrm{~K}^{-1}\right)$. This rubber-based anisotropic material, characterized by a layered segregated filler morphology, represents an important step toward real applications of anisotropic materials, exhibiting a combination of high EMI shielding, thermal conductivity and heat-dissipation capability.

\section{Experimental}

\section{Materials}

Pre-vulcanized natural rubber latex (HMR 10, solid content: $60.5 \mathrm{wt} \%$ ) was supplied by Synthomer, UK. Hexagonal boron nitride, $h \mathrm{BN}$ (CAS: 10043-11-5) was obtained from Alfa Aesar. Carbon nanotubes (NC 7000, diameter: $10 \mathrm{~nm}$, length: $1.5 \mu \mathrm{m}$, density: $1.75 \mathrm{~g} \mathrm{~cm}^{-3}$ ) were purchased from Nanocyl S.A., Belgium. Graphite, mesh 100, was purchased from Sigma Aldrich. Cetyltrimethylammonium bromide (CTAB), as a surfactant, was obtained from Sigma Chemical Company. All reagents were used without further purification.

\section{Exfoliation of boron nitride}

A mixture of the bulk layered boron nitride (100 g) and the solvent (10 L of NMP, Sigma Aldrich) is prepared and exfoliated using a Wet Jet Mill (JN100, Joko, Japan). The Wet Jet Mill apparatus consists of a hydraulic mechanism and a piston, which supplies pressure (250 $\mathrm{MPa}$ ) pushing the boron nitride and NMP mixture into the processor, in which jet streams, high shear rates and cavitation are generated. ${ }^{44,45}$ The mixture of bulk boron nitride and NMP is placed in a container and processed using a $0.10 \mathrm{~mm}$ nozzle diameter. The sample is totally processed, setting the piston passes at 1000 . The process is repeated 10 times to guarantee the processing 
of the whole sample. The processed sample is then collected in a second container. The flake lateral sizes and thickness are reported in ref. 47 indicating a lateral size of $360 \mathrm{~nm}$ and thickness mode of $2.4 \mathrm{~nm}$. The full characterisation of the $h \mathrm{BN}$ flakes is reported in ESI Fig. S1a to c. $\dagger$

\section{Exfoliation of graphite}

A mixture of graphite (100 g) and the solvent (10 L of NMP) is prepared and exfoliated using a Wet Jet Mill (JN100, Joko, Japan). ${ }^{47-49}$ The mixture of graphite and NMP is placed in a container and processed using consecutive nozzles with diameters of $0.3,0.15$ and $0.10 \mathrm{~mm}$. The process is repeated 2 times using the $0.10 \mathrm{~mm}$ nozzle. The processed sample is then collected in a second container. The flake lateral sizes and thickness are reported in ref. 47 indicating a lateral size of $460 \mathrm{~nm}$ and thickness mode of $1.6 \mathrm{~nm}$. The full characterisation of the few-layer graphene flakes is reported in ESI Fig. S1d to $f . \dagger$

\section{Preparation of the composites with a layered-structure}

Measured amounts of CNTs and CTAB with a CNTs/CTAB weight ratio of $1: 1$ were dispersed in water by using an ultrasound probe (UP200S Hielscher sonic bath, the temperature was controlled with an ice-water mixture in a beaker, cycle: 0.5 , amplitude: $80 \%$ ) for $30 \mathrm{~min}$. Pre-vulcanized natural rubber latex was added into the CNT dispersion and further sonicated for $30 \mathrm{~min}$, realizing $\mathrm{NR} / \mathrm{CNT}$ latex. $\mathrm{NR} / h \mathrm{BN}$ latex was obtained through the same procedure. The experimental formulation of latex composites is shown in Table S1. $\dagger$

NR/CNT latex ( $6 \mathrm{ml}$ ) was placed in a Buchner funnel and filtered by vacuum-assisted filtration to deposit the first composite layer on the paper filter. The CNTs, initially assembled onto the surface of rubber latex particles, give rise to an LBL morphology in the samples, Fig. 1. Subsequently, NR/hBN

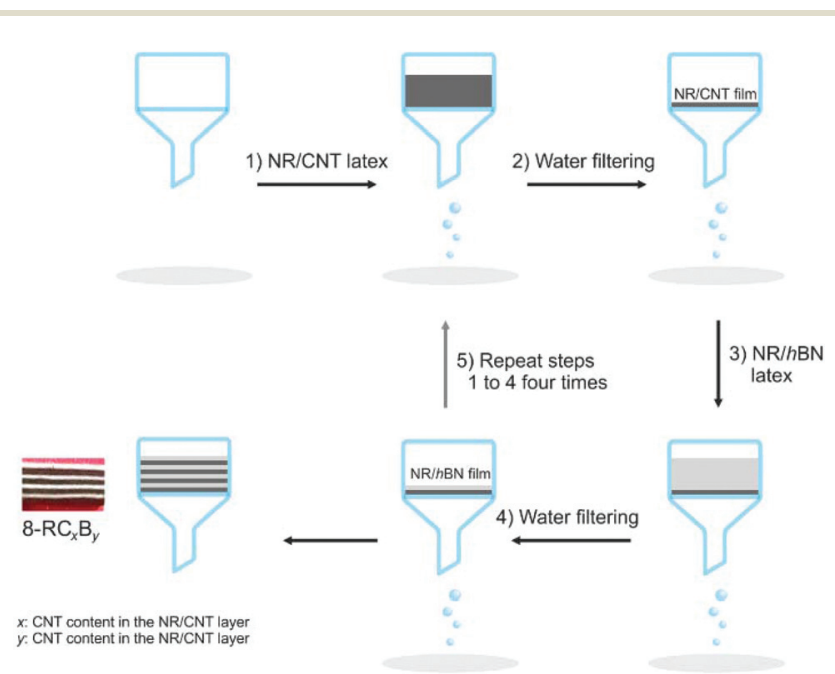

Fig. 1 Schematic illustration of the preparation process of RCB composites with a layered structure. The picture shows the $8-\mathrm{RC}_{8} \mathrm{~B}_{8}$ composite. The same process was adopted to produce some layered structures by using graphene as an alternative to carbon nanotubes. latex $(6 \mathrm{ml})$ was poured on the first layer made of NR/CNTs (black NR/CNT layer) and water was removed by filtration, forming the second layer (white $\mathrm{NR} / h \mathrm{BN}$ layer). These steps were repeated until the desired number of layers was achieved. Finally, the films were dried at $60{ }^{\circ} \mathrm{C}$ for $6 \mathrm{~h}$ and then heated at $150{ }^{\circ} \mathrm{C}$ for $30 \mathrm{~min}$ in a vacuum oven to vulcanize the natural rubber. The obtained films were designated as $z-\mathrm{RC}_{x} \mathrm{~B}_{y}$, where $z$ represents the total number of layers, $x$ and $y$ represent the $\mathrm{CNT}$ and $h \mathrm{BN}$ content in the layers, respectively. For a comparative purpose, $\mathrm{NR} /$ graphene/ $h \mathrm{BN}$ composites were prepared by using the same process, replacing CNTs with graphene and $h \mathrm{BN}$ filler.

\section{Characterization}

Transmission electron microscopy (TEM) images of RCB composites were obtained by using an FEI Tecnai G $^{2}$ F20 S-TWIN transmission electron microscope, operating at an acceleration voltage of $200 \mathrm{kV}$. The samples were sliced at room temperature (70-80 nm thickness) using a cryo-microtomed Leica EM UC6 equipment. The cut films were collected and supported on copper grids for observation.

Scanning electron microscopy (SEM) was conducted using a Zeiss Ultra 55 apparatus (Jena, Germany) with a detector operating at an acceleration voltage of $10 \mathrm{kV}$. Specimens were sputter-coated with $10 \mathrm{~nm}$ gold before measurement using an EMS550X sputter coating system. In order to evaluate the effect of bending cycles at the interface between two layers, samples are bent at $90^{\circ}$ for 1000 cycles and subsequently SEM analysis was performed. Moreover, SEM investigations of tensile fracture surfaces of the samples were also executed. The chemical composition of the films was analysed by X-ray energy dispersive spectroscopy (EDS, Oxford Instruments, coupled to a SEM microscope), by applying $3 \mathrm{keV}$ acceleration voltage under $8.5 \mathrm{~mm}$ working distance.

The thermal conductivity $\left(\kappa, \mathrm{W} \mathrm{m} \mathrm{m}^{-1} \mathrm{~K}^{-1}\right)$ of RCB composites was calculated from the thermal diffusivity $\left(\alpha, \mathrm{mm}^{2} \mathrm{~s}^{-1}\right)$, specific heat capacity $\left(C_{\mathrm{p}}, \mathrm{J} \mathrm{g}^{-1}{ }^{\circ} \mathrm{C}^{-1}\right)$, and the density $(\rho, \mathrm{g}$ $\mathrm{cm}^{-3}$ ), using the relationship $\kappa=\alpha \times C_{\mathrm{p}} \times \rho .^{32}$

The thermal diffusivity of RCB discs (diameter of $12.7 \mathrm{~mm}$ ) was measured at $25^{\circ} \mathrm{C}$ using a laser-flash apparatus (LFA 467, Netzsch Instruments, Inc.).

TA Discovery Differential Scanning Calorimetry, DSC instrument was used to estimate the $C_{\mathrm{p}}$ of RCBs with different filler contents. All samples were heated from 0 to $100{ }^{\circ} \mathrm{C}$, then cooled down to $0{ }^{\circ} \mathrm{C}$ and finally re-heated up to $100{ }^{\circ} \mathrm{C}$ at the rate of $10{ }^{\circ} \mathrm{C} \mathrm{min}^{-1}$. The DSC curve of the second heating ramp was used in order to obtain the $C_{\mathrm{p}}$ value at $25{ }^{\circ} \mathrm{C}$. Density was calculated as the ratio of the mass to volume of the sample. The mass was measured with an analytical balance with a precision of $0.001 \mathrm{~g}$, whereas the sample volume was determined by the geometrical shape and the dimensions were measured by using a calliper with an accuracy of $0.01 \mathrm{~mm}$.

The electrical conductivity of all composites was measured by a two-point measurement (Keithley 2400 picoammeter). Rectangular samples $\left(10 \times 5 \times 1.4 \mathrm{~mm}^{3}\right)$ were cut and coated 
with a silver epoxy paste (Shenzhen Sinwe New Material Co. Ltd) to ensure good electrical contact between picoammeter electrodes and the sample surface.

Thermogravimetric analysis (TGA) was carried out using a TGA Q500 (TA Instrument) in an air atmosphere to characterize the thermal stability of samples. The samples were heated from $30^{\circ} \mathrm{C}$ to $700{ }^{\circ} \mathrm{C}$ at a heating rate of $10^{\circ} \mathrm{C} \mathrm{min}^{-1}$.

Fourier-transform infrared spectroscopy (FTIR) spectra were recorded at room temperature by using a FT-IR spectrometer (model Frontier Dual Ranger, PerkinElmer, USA) in attenuated total reflectance (ATR) mode from $650-4000 \mathrm{~cm}^{-1}$. ATR spectra were recorded at $4 \mathrm{~cm}^{-1}$ resolution, and the reported results are the average of 32 scans. All the spectra were backgroundcorrected.

To evaluate the electric heating behaviour, silver-coated samples $\left(10 \times 5 \times 1.4 \mathrm{~mm}^{3}\right)$ were connected by copper wires to the DC power supply. An IR camera (FLIR A35) was used to record the temperature of the surface of samples at different input voltages. The DC power supply was interrupted when the surface temperature reached $170{ }^{\circ} \mathrm{C}$.

The EMI SE of the samples (thickness of $1.4 \mathrm{~mm}$ ) was evaluated by using an Agilent N5247A vector network analyser in the transmission-reflection mode. The scattering parameters $\left(S_{11}\right.$ and $S_{21}$ ) in the frequency range between 8.2 and $12.4 \mathrm{GHz}$ (X-Band) were recorded. From the $S_{11}$ and $S_{21}$ scattering parameters, the power coefficients of reflectivity $(R)$, transmissivity $(T)$, and absorptivity $(A)$ are obtained using the following equations: ${ }^{50}$

$$
\begin{gathered}
R=\left|S_{11}\right|^{2} \\
T=\left|S_{21}\right|^{2} \\
A=1-R-T
\end{gathered}
$$

Therefore, the effective absorbance $\left(A_{\text {eff }}\right)$ can be described as follows: ${ }^{20}$

$$
A_{\text {eff }}=A /(A+T)
$$

The total EMI SE $\left(\mathrm{SE}_{\mathrm{T}}\right)$, defined as the logarithmic ratio of incoming $\left(P_{\text {in }}\right)$ to outgoing power $\left(P_{\text {out }}\right)$ of electromagnetic radiation was also calculated, according to eqn (5): ${ }^{51}$

$$
\mathrm{SE}_{\mathrm{T}}=-10 \lg \left(\frac{P_{\text {out }}}{P_{\text {in }}}\right)=\mathrm{SE}_{\mathrm{R}}+\mathrm{SE}_{\mathrm{A}}+\mathrm{SE}_{\mathrm{M}}
$$

in which $\mathrm{SE}_{\mathrm{A}}, \mathrm{SE}_{\mathrm{R}}$, and $\mathrm{SE}_{\mathrm{M}}$ are the absorption, reflection, and multiple reflection shielding, respectively. The $\mathrm{SE}_{\mathrm{R}}$ and the sum of $\mathrm{SE}_{\mathrm{A}}$ and $\mathrm{SE}_{\mathrm{M}}$ can be obtained from eqn (6) and (7): ${ }^{50}$

$$
\begin{gathered}
\mathrm{SE}_{\mathrm{R}}=-10 \lg (1-R) \\
\mathrm{SE}_{\mathrm{A}}+\mathrm{SE}_{\mathrm{M}}=-10 \lg \left(\frac{T}{1-R}\right)
\end{gathered}
$$

in which $T$ and $R$ are the transmissivity and reflectivity, respectively, as defined by eqn (1) and (4).

\section{Results and discussion}

\section{Segregated layered morphology and structure of RCB composites}

The layered structure of the $8-\mathrm{RC}_{8} \mathrm{~B}_{8}$ sample is evident in the image in Fig. 1, in which the black layers correspond to the $\mathrm{NR} / \mathrm{CNT}$ composite and the white ones to the $\mathrm{NR} / h \mathrm{BN}$ layers. Each layer displays a uniform thickness (about $190 \mu \mathrm{m} \pm$ $19 \mu \mathrm{m})$, as shown in Fig. S2a, $\uparrow$ which is attributed to the reliability and robustness of the vacuum-assisted filtration process. The NR/CNT layer is well joined to the $\mathrm{NR} / h \mathrm{BN}$ layer, as a result of a wet-wet deposition step, and a sharp interface without cracks between the two layers is observed (Fig. S2b $\dagger$ ). A merged interface between adjacent layers is observed for the sample $8-\mathrm{RC}_{8} \mathrm{~B}_{12}$ all over its longitudinal section. Furthermore, the same merged interfaces can be observed for the $8-\mathrm{RC}_{2} \mathrm{~B}_{8}$ sample subjected to bending at $90^{\circ}$ for 1000 cycles (Fig. S2c $\dagger$ ) and after tensile deformation until breaking (Fig. S2d $\dagger$ ). These results prove that the interface between adjacent layers is sufficiently strong to resist stress and preserve the layered structure from delamination. The boundary between layers is also observable by SEM and TEM, shown, in Fig. 2a and $\mathrm{f}$ respectively. For clarity reasons, the red dotted line is used as eye-guide (Fig. 2f). The presence of such interfaces suggests that the NR latex containing the filler does not penetrate the compact layer, already deposited during the filtration process. The segregated morphology of $h \mathrm{BN}$ nanoparticles and CNTs in the composite layer of the $8-\mathrm{RC}_{8} \mathrm{~B}_{12}$ sample is shown in Fig. 2b-e. The filler morphology of composite $8-\mathrm{RC}_{8} \mathrm{~B}_{8}$ is shown in Fig. $2 \mathrm{f}$ and $\mathrm{h}$. Compared to the $8-\mathrm{RC}_{8} \mathrm{~B}_{8}$ sample, the $8-\mathrm{RC}_{8} \mathrm{~B}_{12}$ sample exhibits a better defined segregated $h \mathrm{BN}$ morphology due to the presence of a larger amount of the $h \mathrm{BN}$ filler. The segregated networks demonstrate that the fillers remain encapsulated in the rubber particles during the latex mixing stage, forming a three-dimensional network during filtration when the filler is forced between the latex particles. To highlight the structure of the segregated $h \mathrm{BN}$ network, SEM and energy-dispersive X-ray spectroscopy images (EDS, including the contribution of $\mathrm{B}$ and $\mathrm{N}$ elements in the $\mathrm{NR} / h \mathrm{BN}$ layer of the $8-\mathrm{RC}_{8} \mathrm{~B}_{8}$ composite) are shown in Fig. $2 \mathrm{i}-\mathrm{k}$ and Fig. S3. $\dagger$ It is noted that $\mathrm{B}$ element and $\mathrm{N}$ element dots, which identify the $h \mathrm{BN}$ platelets.

\section{Through-plane thermal conductivity of RCB composites}

The thermal conductivity in the through-plane direction of the RCB composites increases with the filler content, as illustrated in Fig. 3a. The thermal conductivity value for the $8-\mathrm{RC}_{8} \mathrm{~B}_{12}$ composite is $0.25 \mathrm{~W} \mathrm{~m}^{-1} \mathrm{~K}^{-1}$, which is about $50 \%$ higher than that of pristine $\mathrm{NR}\left(0.17 \mathrm{~W} \mathrm{~m}^{-1} \mathrm{~K}^{-1}\right)$. The higher thermal conductivity can be ascribed to both the high thermal conductivity of CNTs $\left(3000 \mathrm{~W} \mathrm{~m}^{-1} \mathrm{~K}^{-1}\right)^{52}$ and $h \mathrm{BN}\left(600 \mathrm{~W} \mathrm{~m}^{-1} \mathrm{~K}^{-1}\right)^{53}$ nanoparticles (which form the segregated network between rubber particles and provide effective heat conductive paths ${ }^{37,54}$ ), and to the healed interface between the adjacent layers (which make contact between adjacent layers and provide an effective heat transport medium in the through-plane direction). 

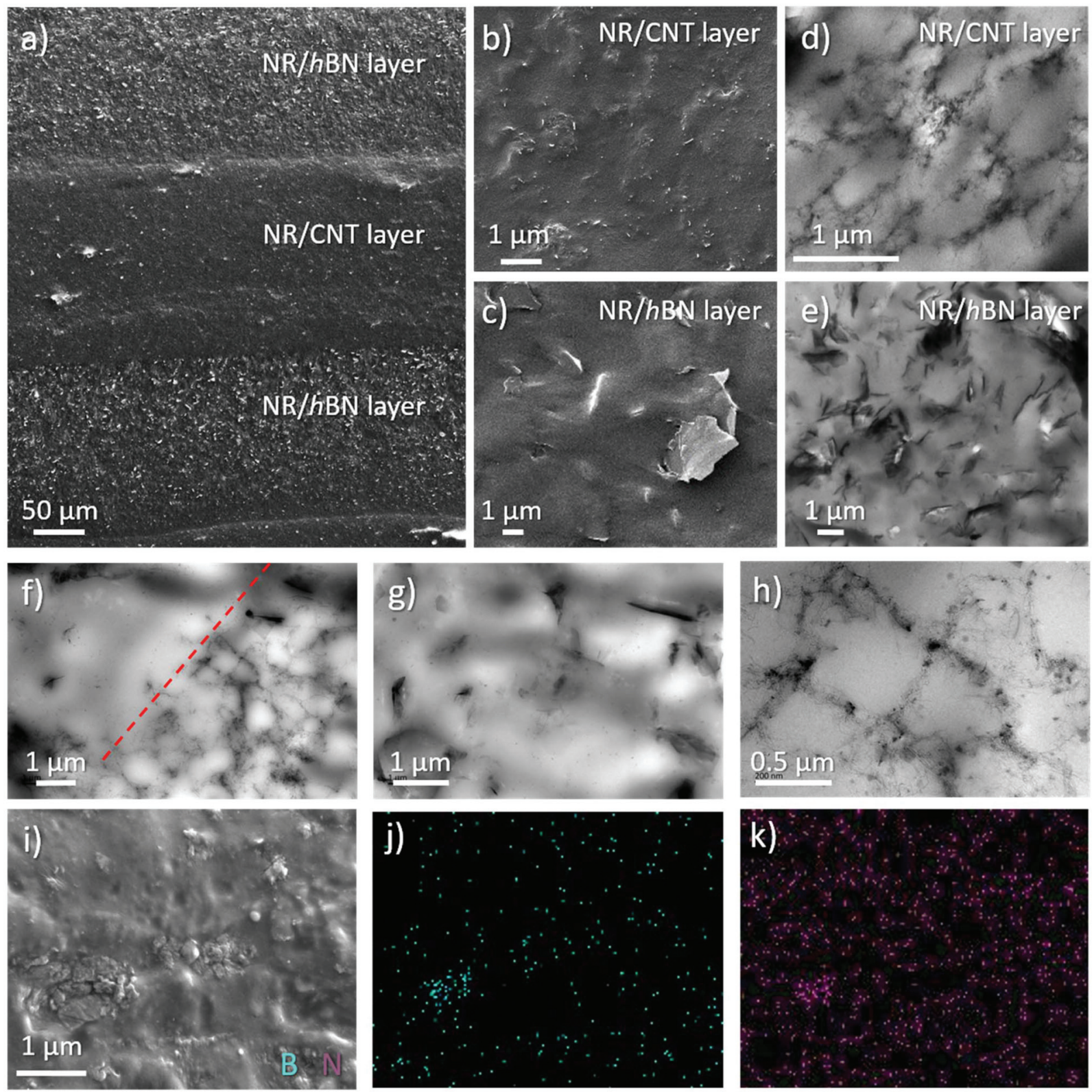

Fig. 2 SEM images of the section surface of the $8-R^{2} C_{8} B_{12}$ composite (a), NR/CNT layer (b) and NR/hBN layer (c). TEM images of the NR/CNT layer (d) and the NR/hBN layer (e). A TEM image of the interface zone between two joined layers ( $f$ ), NR/hBN layer (h) and NR/CNT layer (j) for $8-R C_{8} B_{8}$ composites. SEM image (i), B mapping ( $\mathrm{j}$ ) and $\mathrm{N}$ mapping (k) of $8-\mathrm{RC}_{8} \mathrm{~B}_{8}$ composites.
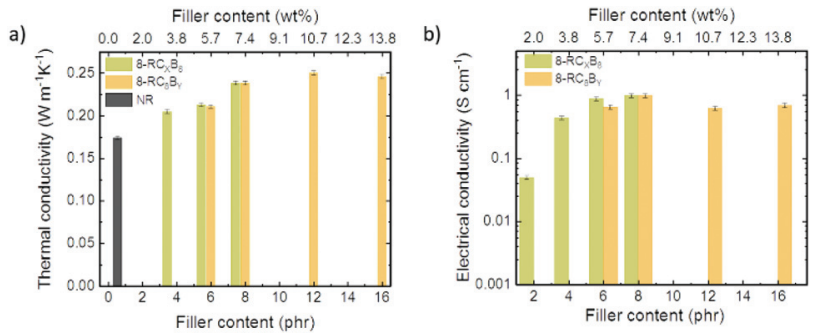

Fig. 3 (a) Thermal conductivity of RCB composites in the throughplane direction. (b) The electrical conductivity of $8-\mathrm{RC}_{x} \mathrm{~B}_{y}$ composites.
It is worth noting that the total or even partial substitution of CNTs with graphene brings a $100 \%$ increment in the thermal conductivity compared to the pristine NR sample, the

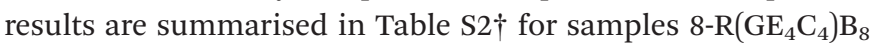
and $8-\mathrm{RGE}_{8} \mathrm{~B}_{8}$ (exhibiting a thermal conductivity of $0.35 \mathrm{~W}$ $\mathrm{m}^{-1} \mathrm{~K}^{-1}$ ), which is ascribed to the presence of graphene flakes (thermal conductivity of $5000 \mathrm{~W} \mathrm{~m}^{-1} \mathrm{~K}^{-1}$ ). ${ }^{55}$ Fig. S3† shows the variation of the heat capacity, $C_{\mathrm{p}}$ for the RCB composites at $25{ }^{\circ} \mathrm{C}$ with the increase of the filler content. In particular, the $C_{\mathrm{p}}$ decreases with the addition of CNTs or the $h \mathrm{BN}$ filler due to the intrinsically lower $C_{\mathrm{p}}$ of CNTs $\left(0.65 \mathrm{~J} \mathrm{~g}^{-1} \mathrm{~K}^{-1}\right)^{56}$ and $h$ BNs $\left(0.78 \mathrm{~J} \mathrm{~g}^{-1} \mathrm{~K}^{-1}\right)^{57}$ compared to the pristine NR $\left(2.00 \mathrm{~J} \mathrm{~g}^{-1}\right.$ 
$\mathrm{K}^{-1}$ ). Taking into account that the $C_{\mathrm{p}}$ decreases with the filler content and that the density of the composite does not change significantly, it is possible to confirm that the thermal diffusivity, $\alpha$, is the key parameter to control the thermal conductivity of LBL composites. By increasing the filler content, the thermal diffusivity increases as a consequence of the thermal phonon exchange due to the densification of the three-dimensional filler network and increase of overlapping between particles, as shown in the section related to the morphology. ${ }^{58}$

\section{The in-plane electrical conductivity of RCB composites}

The electrical conductivity of the RCB composites affects greatly their electro-heating behaviour and EMI shielding performance. By cutting-off the conductive path with the insulating $\mathrm{NR} / h \mathrm{BN}$ layer, the RCB composites become electrical insulators in the through-plane direction (Fig. S5a $\dagger$ ), while RCB composites are conductive in the in-plane direction (Fig. S5b $\dagger$ ). The in-plane electrical conductivity data of $8-\mathrm{RC}_{x} \mathrm{~B}_{y}$ composites are displayed in Fig. $3 \mathrm{~b}$, showing that the electrical conductivity of $8-\mathrm{RC}_{x} \mathrm{~B}_{8}$ composites increases with increasing CNT content, which is ascribed to the formation of a more effective conductive network. ${ }^{39}$ In particular, the electrical conductivity of $8-\mathrm{RC}_{8} \mathrm{~B}_{8}$ is $0.98 \mathrm{~S} \mathrm{~cm}^{-1}$, which is similar to the values exhibited by some of our previous NR/CNT composites (CNT content: $\left.8 \mathrm{phr}, 0.30 \mathrm{~S} \mathrm{~cm}^{-1}\right)^{5}$ and by NR/CNT composites (CNT content: $10 \mathrm{wt} \%, 1.31 \mathrm{~S} \mathrm{~cm}^{-1}$ ) published by Jia et al. ${ }^{41}$ The results suggest that the effective CNT segregated network is preserved during the filtration process, as shown in Fig. 2. From the data reported in Table $\mathrm{S} 2, \uparrow$ it is possible to see that the electrical conductivity of $8-\mathrm{RC}_{8} \mathrm{~B}_{8}\left(0.98 \mathrm{~S} \mathrm{~cm}^{-1}\right)$ is higher than the ones of the $8-\mathrm{R}\left(\right.$ graphene $\left._{4} \mathrm{C}_{4}\right) \mathrm{B}_{8}\left(0.234 \mathrm{~S} \mathrm{~cm}^{-1}\right)$ and 8 - $\mathrm{R}\left(\right.$ graphene $\left._{8}\right) \mathrm{B}_{8}\left(3.98 \times 10^{-5} \mathrm{~S} \mathrm{~cm}^{-1}\right)$ samples. The satisfactory electrical conductivity of the RCB composites is also demonstrated by the gleaming of a light emitting diode (LED) bulb connected to the battery through an electrical circuit that includes the $8-\mathrm{RC}_{8} \mathrm{~B}_{12}$ composite (Fig. S5c $\dagger$ ). Furthermore, it is noted that the electrical conductivity of RCB composites decreases with increasing $h \mathrm{BN}$ content from $8 \mathrm{phr}$ to $16 \mathrm{phr}$. This behaviour can be ascribed to the effect of accumulation of CTAB in the layers with CNTs, which occurs during the filtration. Likely, the surfactant, coming from the layers with $h \mathrm{BN}$, deposits onto the surface of CNTs leading to an increase of the distance between them and reducing, consequently, the effect of electron tunnelling transport. ${ }^{59}$ This hypothesis is supported by FTIR results for NR/CNT layers and $\mathrm{NR} / h \mathrm{BN}$ layers which show an accumulation of CTAB in the CNT layers of composite samples with higher contents of $h \mathrm{BN}$ (Fig. S6†).

\section{EMI shielding property of RCB composites}

The EMI SE behaviour of materials depends on the reflection and absorption of the incident EM waves at the interfaces between both air/material, between different materials and within the material. ${ }^{20}$ In particular, the reflection contribution $\mathrm{SE}_{\mathrm{R}}$ is related to the impedance mismatch between the air and the material, ${ }^{20}$ in which the absorption, $\mathrm{SE}_{\mathrm{A}}$ depends on the conduction, polarization and magnetic losses of the adsorbing materials. ${ }^{33}$ In the case of multiple reflections, $\mathrm{SE}_{\mathrm{M}}$ is often neglected for isotropic materials, ${ }^{20}$ i.e. when the thickness of the sample is much greater than the skin depth (which represents the penetration distance of radiation in the materials at which the intensity transmitted is reduced to $1 / e$ of its initial value). In our cases, multiple reflections (i.e., air/ material, material/air and material based on CNT/materials based on $h \mathrm{BN}$ ) cannot be neglected since each layer is about $190 \mu \mathrm{m} \pm 19 \mu \mathrm{m}$ (as shown by SEM images, Fig. S2a $\dagger$ ).

Since the impedance mismatch between the air and the $\mathrm{NR} / \mathrm{CNT}$ layer is different from that between the air and the $\mathrm{NR} / h \mathrm{BN}$ layer, the EMI shielding property of RCB composites (1.4 $\mathrm{mm}$ in thickness) was measured with respect to the incident directions of the EM wave, i.e., (a) EM waves entering into the sample through the NR/CNT layer and (b) through the NR/ $h \mathrm{BN}$ layer, as shown in Fig. 4. In particular, the EMI SE was determined in the range of 8.2-12.4 GHz, which represents the working frequency band for transmission radar communication and for most electronic devices, i.e. wireless devices such as cell phone, tablets, televisions, computers, and supercomputers. ${ }^{1}$ The data show that the EMI SE of all samples increases with the frequency, regardless of the direction of the incident waves, as shown in Fig. 4a and b. Moreover, although the density of RCB composites does not change with the filler content (Fig. S7 $\dagger$ ) their EMI SE does. The increase of EMI SE is attributed to the increment of free-charge carriers and electric dipoles, together with the enhanced conductive network. ${ }^{42}$ In particular, the EMI SE of $8-\mathrm{RC}_{4} \mathrm{~B}_{8}$ is $22.68 \pm 0.2 \mathrm{~dB}$ at 10.3 $\mathrm{GHz}$, when the EM waves penetrate into the samples from the NR/CNT layer. This value satisfies the commercial EMI shielding requirement $(20 \mathrm{~dB})$ for shielding materials. ${ }^{20}$ Moreover, by increasing the $h \mathrm{BN}$ content, the $8-\mathrm{RC}_{8} \mathrm{~B}_{y}$ composites show a further increment of EMI SE values, i.e., the EMI SE values for $8-\mathrm{RC}_{8} \mathrm{~B}_{6}$ and $8-\mathrm{RC}_{8} \mathrm{~B}_{16}$ are $26.29 \pm 0.2$ and $29.93 \pm 0.2 \mathrm{~dB}$, respectively, at $10.3 \mathrm{GHz}$. The increment of EMI SE is ascribed to a denser and more interconnected $h \mathrm{BN}$ network, allowing greater availability of pathways for the movement of charges from the CNT layer to the $h \mathrm{BN}$ layer through a hopping mechanism. ${ }^{60}$ However, it is also possible that an increase in the $h \mathrm{BN}$ content brings a significant impedance mismatch between the $\mathrm{NR} / h \mathrm{BN}$ and the NR/CNT layers, thereby enhancing the internal reflections of EM. It is worth mentioning that the RCB composites exhibit higher EMI SE values when the $\mathrm{EM}$ waves enter into the samples from the $\mathrm{NR} / h \mathrm{BN}$ layer (Fig. 4b). In fact, the EMI SE values of $8-\mathrm{RC}_{8} \mathrm{~B}_{8}$ and $8-\mathrm{RC}_{8} \mathrm{~B}_{16}$ are $30.49 \pm 0.2$ and $32.52 \pm 0.2 \mathrm{~dB}$, respectively, at $10.3 \mathrm{GHz}$. To understand the mechanisms involved in the electromagnetic shielding effect of RCB composites, the different contributions $\mathrm{SE}_{\mathrm{A}}+\mathrm{SE}_{\mathrm{M}}, \mathrm{SE}_{\mathrm{R}}$ and $\mathrm{SE}_{\mathrm{T}}$ for $8-\mathrm{RC}_{x} \mathrm{~B}_{8}$ and $8-\mathrm{RC}_{8} \mathrm{~B}_{y}$ composites, have been included in Fig. $4 \mathrm{c}$ and $\mathrm{d}$. The values of $\mathrm{SE}_{\mathrm{A}}+\mathrm{SE}_{\mathrm{M}}$ and $\mathrm{SE}_{\mathrm{T}}$ for $8-\mathrm{RC}_{8} \mathrm{~B}_{y}$ and $8-\mathrm{RC}_{x} \mathrm{~B}_{8}$ composites increase with the filler content, while $\mathrm{SE}_{\mathrm{R}}$ does not change significantly. In particular, the $\mathrm{SE}_{\mathrm{R}}$ value $(\sim 1 \mathrm{~dB})$ when the waves traverse the sample from the $\mathrm{NR} / h \mathrm{BN}$ layer is lower than that $(\sim 5 \mathrm{~dB})$ when the waves traverse the sample from the NR/CNT layer. The phenomenon is attributed to the impedance mismatch 
a)
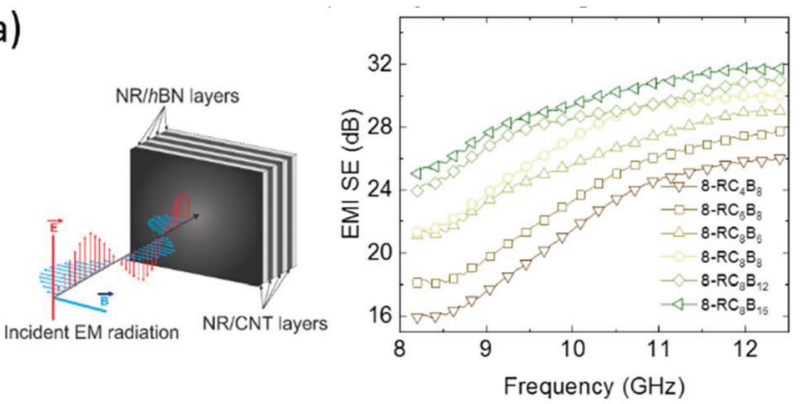

d)

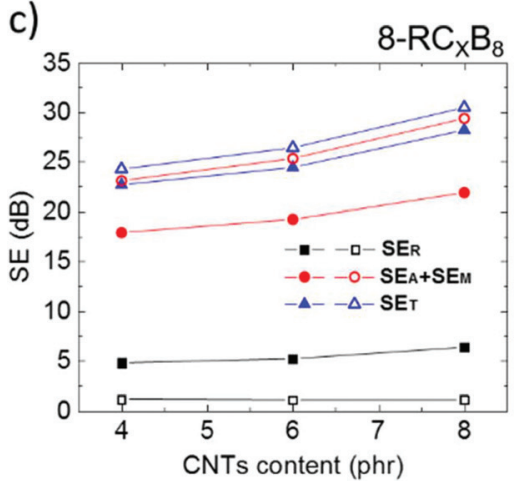

b)

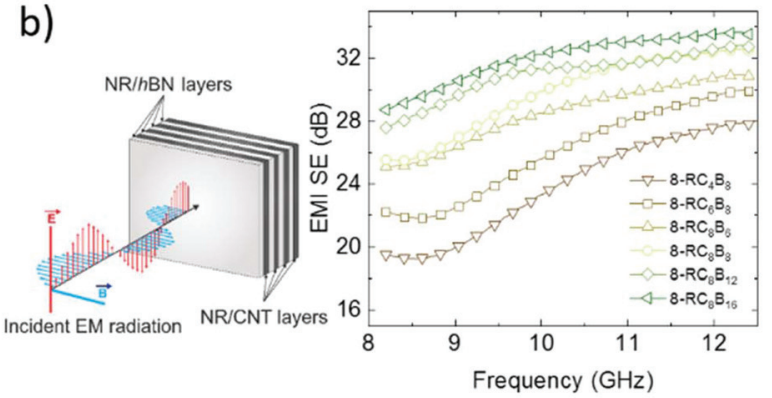

Filler content (wt\%)

e)
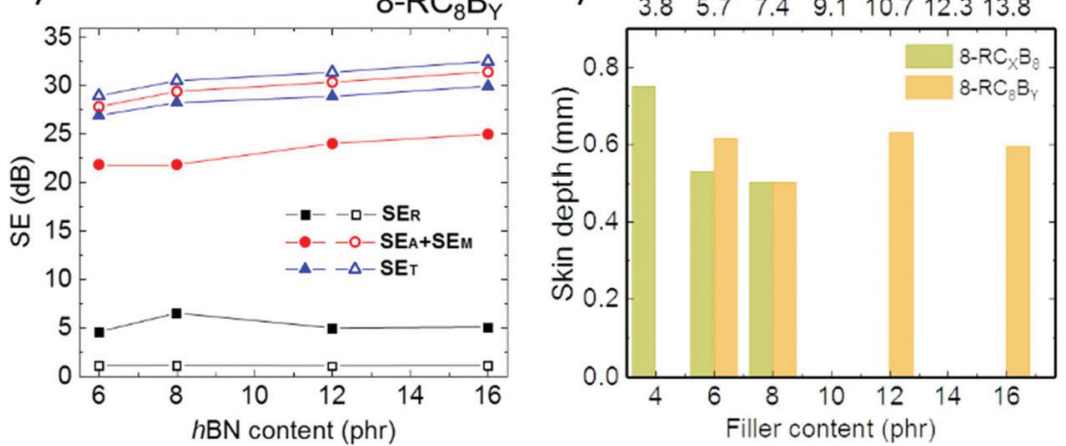

Fig. 4 (a) Electromagnetic waves are incident from the NR/CNT layer; EMI SE of RCB composites with different filler contents as a function of frequency when EM waves penetrate the samples from the NR/CNT layer; (b) EM waves enter from the NR/ $h B N$ layer. EMI SE of RCB composites with different filler contents as a function of frequency when EM waves penetrate the samples from the NR/ $h B N$ layer; (c) shielding by reflection, absorption and multiple reflections, and total shielding of $8-\mathrm{RC}_{x} \mathrm{~B}_{8}$ composites at $10.3 \mathrm{GHz}$ (solid symbol: EM waves enter from the NR/CNT layer; hollow symbol: EM waves enter from the NR/hBN layer). (d) Shielding by reflection, absorption and multiple reflections, and total shielding of $8-\mathrm{RC}_{8} \mathrm{~B}_{y}$ composites at $10.3 \mathrm{GHz}$ (solid symbol: EM waves enter from the NR/CNT layer; hollow symbol: EM waves enter from the NR/hBN layer). (e) The skin depth of the $8-\mathrm{RC}_{x} \mathrm{~B}_{8}$ and $8-\mathrm{RC}_{8} \mathrm{~B}_{y}$ composites, in the hypothesis the multiple reflections are neglected. The sample thickness is 1.4 mm. Error bar of the Agilent N5247A vector network analyser was $0.2 \mathrm{~dB}$.

between air and the $\mathrm{NR} / \mathrm{hBN}$ layer which is lower compared to the mismatch between air and the NR/CNT layer. Furthermore, for all 8- $\mathrm{RC}_{x} \mathrm{~B}_{y}$ composites, the contribution of $\mathrm{SE}_{\mathrm{A}}+\mathrm{SE}_{\mathrm{M}}$ to the total EMI SE is more than $98 \%$, as shown in Fig. S8. $\dagger$ These results confirm that the EM wave absorption and multiple reflections are the key mechanisms mainly contributing to the EMI SE of 8-RC $\mathrm{B}_{x}$ composites, which implies that the layered structure and the filler segregated morphology improve the adsorption of EM rather than reflect it into the surroundings. However, the RCB composites exhibit the highest $\mathrm{SE}_{\mathrm{A}}+$ $\mathrm{SE}_{\mathrm{M}}$, and lowest $\mathrm{SE}_{\mathrm{R}}$ contributions when the $\mathrm{EM}$ waves enter from the $\mathrm{NR} / h \mathrm{BN}$ layer and leave from the $\mathrm{NR} / \mathrm{CNT}$ layer. In particular, the data in Fig. $4 \mathrm{c}$ and d show that the $\mathrm{SE}_{\mathrm{A}}+\mathrm{SE}_{\mathrm{M}}$ of RCB composites measured when EM waves are incident from $\mathrm{NR} / h \mathrm{BN}$, is always higher than $\mathrm{SE}_{\mathrm{T}}$ obtained when $\mathrm{EM}$ waves enter from the NR/CNT layer at $10.3 \mathrm{GHz}$. Thus, the results confirm that the best configuration to increase the shielding effectiveness is achieved when the EM waves enter the sample from the NR/hBN layer and leave from the NR/CNT layers. To further evaluate the EMI shielding performance it is useful to use the normalized EMI SE values (i.e. EMI SE divided by sample thickness). The specific EMI SE value of the $8-\mathrm{RC}_{8} \mathrm{~B}_{12}$ composite (1.4 mm thickness) is equal to $20.62 \pm 0.14 \mathrm{~dB}$ $\mathrm{mm}^{-1}$ when the EM wave enters from the NR/CNT layer, while it is equal to $22.41 \pm 0.14 \mathrm{~dB} \mathrm{~mm}^{-1}$ when the $\mathrm{EM}$ wave enters from the $\mathrm{NR} / h \mathrm{BN}$ layer at $10.3 \mathrm{GHz}$. Both these EMI values are higher than some of the earlier published values for rubberbased EMI materials (Table S3†).

The skin depth parameter $(\delta)$, is a quantitative measure of the materials' shielding ability. ${ }^{20}$ Moreover, the skin depth is inversely proportional to the $\mathrm{SE}_{\mathrm{A}}$ value of materials at a fixed thickness, $d{ }^{61}$ The relationship between $\mathrm{SE}_{\mathrm{A}}$ and skin depth is given by eqn (8): ${ }^{42}$

$$
\mathrm{SE}_{\mathrm{A}}=20 \log \left(e^{d / \delta}\right)=8.686(d / \delta)
$$

The skin depth depends on the frequency according to eqn $(9):^{42}$

$$
\delta=1 /(\pi f \mu \sigma)^{1 / 2}
$$

where $f$ is the frequency, $\sigma$ is the electrical conductivity of the overall anisotropic composite, and $\mu$ is the magnetic permeability of the material $\left(\mu=\mu_{\mathrm{o}} \mu_{\mathrm{r}}\right.$ where $\mu_{\mathrm{o}}=4 \pi \times 10^{-7} \mathrm{H} \mathrm{m}^{-1}$ and $\mu_{\mathrm{r}}$ is the material's relative magnetic permeability, and $\mu_{\mathrm{r}}$ = 1 for the nonmagnetic composites). Neglecting the multiple reflections from each layer, the skin depth of the samples with more than $4 \mathrm{phr}(\sim 3.8 \mathrm{wt} \%)$ CNT is estimated to be less than $0.7 \mathrm{~mm}$, see Fig. 4e. Since this skin depth value (around 
a)

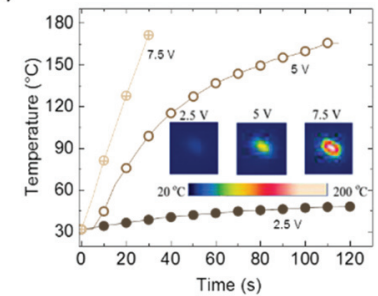

b)

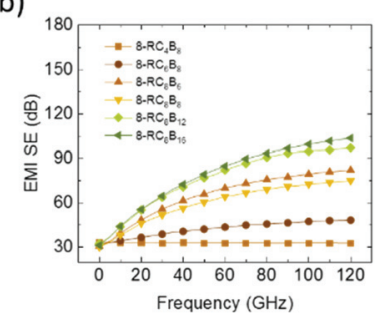

Fig. 5 (a) The time-dependent temperature profiles of $8-R_{4} B_{8}$ composites for the different input voltages. The inset picture is an IR image of the $8-\mathrm{RC}_{4} \mathrm{~B}_{8}$ composite surface after inputting voltage for $30 \mathrm{~s}$. (b) The effect of filler content on the electro heating behaviour with an input voltage of $2.5 \mathrm{~V}$.

$0.7 \mathrm{~mm}$ ) corresponds to the total thickness of the four NR/ CNT layers, it can be deduced that the RCB composites display excellent EMI shielding properties when the CNT concentration of the NR/CNT layers is greater than 4 phr.

\section{Electric heating behaviour of RCB composites}

Materials exhibiting significant electrical conductivity are often used as electric heaters. Electrical energy dissipated by the Joule effect was monitored by infrared imaging of the NR/ $h$ BN surface (Fig. S9†). During the application of the voltage (5 $\mathrm{V})$, the samples exhibited a uniform temperature distribution (inset image of Fig. 5a). The time-dependent temperature profiles of $8-\mathrm{RC}_{4} \mathrm{~B}_{8}$ composites at the different voltages (from 2.5 $\mathrm{V}$ to $7.5 \mathrm{~V}$ ) are shown in Fig. 5a. The surface temperature of $8-\mathrm{RC}_{4} \mathrm{~B}_{8}$ increases to $170{ }^{\circ} \mathrm{C}$ in $30 \mathrm{~s}$ when applying an electric potential of $7.5 \mathrm{~V}$. When the voltage is reduced to $5 \mathrm{~V}$ and $2.5 \mathrm{~V}$ the equilibrium surface temperature of the $8-\mathrm{RC}_{4} \mathrm{~B}_{8}$ composites drastically decreased to $165.4^{\circ} \mathrm{C}$ and $47.8^{\circ} \mathrm{C}$, respectively, suggesting that there is sharp non-linearity (switching effect) in the heat-voltage. ${ }^{61}$ These results confirm that the sample $8-\mathrm{RC}_{4} \mathrm{~B}_{8}$ can be used as a heat dissipater by applying lower heat-voltage as compared to the ones previously reported for graphene/rubber, ${ }^{34}$ i.e. $10 \mathrm{~V}$ and for poly(3,4-ethylene dioxythiophene) textiles, ${ }^{62}$ i.e. $6 \mathrm{~V}$. The heat-voltage is similar to the value found for both the MXene/polyester composite, ${ }^{63}$ i.e., $2 \mathrm{~V}$ and graphene, ${ }^{64}$ i.e., $3.2 \mathrm{~V}$. These low-trigger voltage values not only ensure human body safety when the devices are used as textile heaters but make it also possible to be powered by portable batteries. ${ }^{63}$ The input voltage of $2.5 \mathrm{~V}$ was applied to all 8- $\mathrm{RC}_{x} \mathrm{~B}_{y}$ composites for investigating the effect of filler contents on their electric heating behaviour. The results are shown in Fig. $5 b$.

It is worth noting that the stationary temperature of all samples is reached faster with the increase of the CNT content. The steady-state temperature changes from $32.1^{\circ} \mathrm{C}$ to $96.8^{\circ} \mathrm{C}$ when the CNT content increases from $2 \mathrm{phr}(\sim 2 \mathrm{wt} \%)$ to $8 \mathrm{phr}$, which is attributed to the increase in the electrical conductivity of $8-\mathrm{RC}_{x} \mathrm{~B}_{8}$. It is also significant to note that the surface temperature of $8-\mathrm{RC}_{8} \mathrm{~B}_{y}$ composites increases from $74.6{ }^{\circ} \mathrm{C}$ to $103.3^{\circ} \mathrm{C}$ when the $h \mathrm{BN}$ content increases from 6

phr (5.66 wt $\%)$ to $12 \mathrm{phr}$. That is ascribed to the fact that the thermal conductivity increases with the $h \mathrm{BN}$ content whereas the $C_{\mathrm{p}}$ decreases, suggesting a more significant Joule heating effect from the inner layer to the surface layer. Based on data reported in Table $\mathrm{S} 4, \dagger$ the RCB composites display better electric heating behaviour than epoxy/graphene films, ${ }^{65,66}$ epoxy/ graphene/CNT films ${ }^{66}$ and polydimethylsiloxane/CNT/graphene films ${ }^{67}$ with the same sample size (length and wideness). The thermal stability of electric heating materials affects the temperature range wherein the samples can operate. Based on Fig. S10, $\uparrow$ RCB composites can be safely used below $200^{\circ} \mathrm{C}$, which represents the temperature onset for thermal degradation of samples as determined by TGA in air atmosphere.

\section{Conclusions}

Layered composites containing carbon nanotubes and boron nitride flakes as fillers with a segregated morphology were produced by combining latex mixing and vacuum-assisted filtration methods. These composites have been investigated as potential candidates for both electromagnetic interference (EMI) shielding application in the $8.4-12.4 \mathrm{GHz}$ range and as heater dissipaters. The results confirm, as compared to the state-of-the-art, that the segregated morphology of the fillers and the anisotropic structure built-up by alternating conductive and insulating layers enable the realization of effective multifunctional EMI shielding materials, by exploiting easy and reliable methods. In the through-plane direction, the layered composites, i.e., the $8 \mathrm{phr}$ of carbon nanotubes and 12 phr of boron nitride flakes $\left(8-\mathrm{RC}_{8} \mathrm{~B}_{12}\right)$, display a thermal conductivity up to $0.25 \mathrm{~W} \mathrm{~m}^{-1} \mathrm{~K}^{-1}$, electrical insulation and an EMI shielding of $32.52 \pm 0.2 \mathrm{~dB}$ at $10.3 \mathrm{GHz}$. In the in-plane direction, the layered composites exhibit an electrical conductivity up to $0.98 \mathrm{~S} \mathrm{~cm}^{-1}$, and electric heating behaviour. In particular, the thermal conductivity and specific EMI shielding efficiency of $8-\mathrm{RC}_{8} \mathrm{~B}_{12}$ composites (containing four layers with carbon nanotubes at $8 \mathrm{phr}$ and four layers with boron nitride flakes at $12 \mathrm{phr}$ ) are respectively $0.25 \mathrm{~W} \mathrm{~m}^{-1} \mathrm{~K}^{-1}$ and $22.41 \pm$ $0.14 \mathrm{~dB} \mathrm{~mm}^{-1}$ (EM waves enter from the NR/boron nitride layer). The surface of the same material reaches about $103{ }^{\circ} \mathrm{C}$ with an input voltage of $2.5 \mathrm{~V}$. The present work opens the way to the design of next-generation multifunctional EMI shielding materials for possible use as "smart textiles" that are able to shield electronic devices and are capable of heating as well as dissipating heat emanating from external devices.

\section{Conflicts of interest}

There are no conflicts to declare.

\section{Acknowledgements}

This work was supported by the Joint Laboratory for Graphene-based Multifunctional Polymer Nanocomposites 
founded by CNR (Joint Labs Call 2015-2018), by the Bilateral project GINSENG between NSFC (China) and MAECI (Italy) (2018-2020), by the Natural Science Foundation of Shandong Province (ZR2019QEM009), by the opening project of Guangxi Key Laboratory of Calcium Carbonate Resources Comprehensive Utilization (HZXYKFKT201803), by the Special Foundation for Innovation-Driven Development of Hezhou (PT0710004) and the European Union's Horizon 2020 Research and Innovation Program under grant agreement No. 785219-GrapheneCore2.

\section{Notes and references}

1 P. M. Mariappan, D. R. Raghavan, S. H. E. A. Aleem and A. F. Zobaa, J. Adv. Res., 2016, 7, 727.

2 W.-J. Zhi, L.-F. Wang and X.-J. Hu, Mil. Med. Res., 2017, 4, 29.

3 K. Zhang, G.-H. Li, L.-M. Feng, N. Wang, J. Guo, K. Sun, K.-X. Yu, J.-B. Zeng, T. Li, Z. Guo and M. Wang, J. Mater. Chem. C, 2017, 5, 9359.

4 Y. Zhan, M. Oliviero, J. Wang, A. Sorrentino, G. Buonocore, L. Sorrentino, M. Lavorgna, H. Xia and S. Iannace, Nanoscale, 2019, 11, 1011.

5 H. Abbasi, M. Antunes and J. I. Velasco, Prog. Mater. Sci., 2019, 103, 319.

6 R. Pandey, S. Tekumalla and M. Gupta, Composites, Part B, 2019, 163, 150.

7 J. Jung, H. Lee, I. Ha, H. Cho, K. K. Kim, J. Kwon, P. Won, S. Hongand and S. H. Ko, ACS Appl. Mater. Interfaces, 2017, 9, 44609 .

8 J. Huang, Z. Chen, F. Zhou, H. Wang, Y. Yuan, W. Chen, M. Gao and Y. Zhan, J. Solid State Electrochem., 2017, 21, 1559.

9 Y. Wang, W. Zhang, X. Wu, C. Luo, Q. Wang, J. Li and L. Hu, Synth. Met., 2017, 228, 18.

10 J. Li, G. Zhang, H. Zhang, X. Fan, L. Zhou, Z. Shang and X. Shi, Appl. Surf. Sci., 2018, 428, 7.

11 M. H. Al-Saleh and U. Sundararaj, Carbon, 2009, 47, 1738.

12 A. Gupta and V. Choudhary, Compos. Sci. Technol., 2011, 71, 1563.

13 L. Xu, X.-P. Zhang, C.-H. Cui, P.-G. Ren, D.-X. Yan and Z.-M. Li, Ind. Eng. Chem. Res., 2019, 58, 4454.

14 T. Hasan, Z. Sun, F. Wang, F. Bonaccorso, P. H. Tan, A. G. Rozhin and A. C. Ferrari, Adv. Mater., 2009, 21, 3874.

15 P. Cataldi, F. Bonaccorso, A. E. Del Rio Castillo, V. Pellegrini, Z. Jiang, L. Liu, N. Boccardo, M. Canepa, R. Cingolani, A. Athanassiou and I. S. Bayer, Adv. Electron. Mater., 2016, 2, 1600245.

16 P. Cataldi, I. S. Bayer, G. Nanni, A. Athanassiou, F. Bonaccorso, V. Pellegrini, A. E. Del Rio Castillo, F. Ricciardella, S. Artyukhin, M.-A. Tronche, Y. Gogotsi and R. Cingolani, Carbon, 2016, 109, 331.

17 Y. Li, B. Shen, D. Yi, L. Zhang, W. Zhai, X. Wei and W. Zheng, Compos. Sci. Technol., 2017, 138, 209.
18 M. Cao, C. Han, X. Wang, M. Zhang, Y. Zhang, J. Shu, H. Yang, X. Fang and J. Yuan, J. Mater. Chem. C, 2018, 6, 4586.

19 E. Lago, P. S. Toth, G. Pugliese, V. Pellegrinia and F. Bonaccorso, RSC Adv., 2016, 6, 97931.

20 Y. Zhan, J. Wang, K. Zhang, Y. Li, Y. Meng, N. Yan, W. Wei, F. Peng and H. Xia, Chem. Eng. J., 2018, 344, 184.

21 F. Shahzad, M. Alhabeb, C. B. Hatter, B. Anasori, S. M. Hong, C. M. Koo and Y. Gogotsi, Science, 2016, 353, 1137.

22 Z. Huang, S. Wang, S. Kota, Q. Pan, M. W. Barsoum and C. Y. Li, Polymer, 2016, 102, 119.

23 Y. Tong, M. He, Y. Zhou, X. Zhong, L. Fan, T. Huang, Q. Liao and Y. Wang, Appl. Surf. Sci., 2018, 434, 283.

24 Y. Jiang, X. Xie, Y. Chen, Y. Liu, R. Yang and G. Sui, J. Mater. Chem. C, 2018, 6, 8679.

25 W. Cao, F. Chen, Y. Zhu, Y. Zhang, Y. Jiang, M. Ma and F. Chen, ACS Nano, 2018, 12, 4583.

26 R. Sun, H. Zhang, J. Liu, X. Xie, R. Yang, Y. Li, S. Hong and Z.-Z. Yu, Adv. Funct. Mater., 2017, 27, 1702807.

27 L. Wang, H. Qiu, C. Liang, P. Song, Y. Han, Y. Han, J. Gu, J. Kong, D. Pan and Z. Guo, Carbon, 2019, 141, 506.

28 C. Liang, H. Qi, Y. Han, H. Gu, P. Song, L. Wang, J. Kong, D. Cao and J. Gu, J. Mater. Chem. C, 2019, 7, 2725.

29 Q. Weng, X. Wang, X. Wang, Y. Bando and D. Golberg, Chem. Soc. Rev., 2016, 45, 3989.

30 G. Cassabois, P. Valvin and B. Gil, Nat. Photonics, 2016, 10, 262.

31 X. Zhang, X. Zhang, M. Yang, S. Yang, H. Wu, S. Guo and Y. Wang, Compos. Sci. Technol., 2016, 136, 104.

32 X. Zhang, J. Zhang, C. Li, J. Wang, L. Xia, F. Xu, X. Zhang, H. Wu and S. Guo, Chem. Eng. J., 2017, 328, 609.

33 C.-P. Feng, S.-S. Wan, W.-C. Wu, L. Bai, R.-Y. Bao, Z.-Y. Liu, M.-B. Yang, J. Chen and W. Yang, Compos. Sci. Technol., 2018, 167, 456.

34 M. N. Gueye, A. Carella, R. Demadrille and J.-P. Simonato, ACS Appl. Mater. Interfaces, 2017, 9, 27250.

35 Y. Liu, M. Lu, K. Wu, S. Yao, X. Du, G. Chen, Q. Zhang, L. Liang and M. Lu, Compos. Sci. Technol., 2019, 174, 1.

36 Y. Zhan, Y. Meng and Y. Li, Mater. Lett., 2017, 192, 115.

37 P. Zhang, X. Ding, Y. Wang, Y. Gong, K. Zheng, L. Chen, X. Tian and X. Zhang, Composites, Part A, 2019, 117, 56.

38 H. Chen, V. V. Ginzburg, J. Yang, Y. Yang, W. Liu, Y. Huang, L. Du and B. Chen, Prog. Polym. Sci., 2016, 59, 41.

39 Y. Zhan, M. Lavorgna, G. Buonocore and H. Xia, J. Mater. Chem., 2012, 22, 10464.

40 M. Salzano de Luna, Y. Wang, T. Zhai, L. Verdolotti, G. G. Buonocore, M. Lavorgna and H. Xia, Prog. Polym. Sci., 2019, 89, 213.

41 L.-C. Jia, D.-X. Yan, Y. Yang, D. Zhou, C.-H. Cui, E. Bianco, J. Lou, R. Vajtai, B. Li, P. M. Ajayan and Z.-M. Li, Adv. Mater. Technol., 2017, 2, 1700078.

42 F. Sharif, M. Arjmand, A. A. Moud, U. Sundararaj and E. P. L. Roberts, ACS Appl. Mater. Interfaces, 2017, 9, 14171. 
43 X. Wang and P. Wu, ACS Appl. Mater. Interfaces, 2017, 9, 19934.

44 C. Gao, H. Lu, H. Ni and J. Chen, J. Polym. Res., 2018, 25, 6.

45 C. Feng, H. Ni, J. Chen and W. Yang, ACS Appl. Mater. Interfaces, 2016, 8, 19732.

46 C. Bottier, Adv. Bot. Res., 2020, 93, 201.

47 A. E. Del Rio Castillo, V. Pellegrini, A. Ansaldo, F. Ricciardella, H. Sun, L. Marasco, J. Buha, Z. Dang, L. Gagliani, E. Lago, N. Curreli, S. Gentiluomo, F. Palazon, M. Prato, R. Oropesa-Nuñez, P. S. Toth, E. Mantero, M. Crugliano, A. Gamucci, A. Tomadin, M. Polini and F. Bonaccorso, Mater. Horiz., 2018, 5, 890.

48 A. E. Del Rio Castillo, A. Ansaldo, V. Pellegrini and F. Bonaccorso, International Patent WO2017089987A1, 2015.

49 S. Bellani, E. Petroni, A. E. Del Rio Castillo, N. Curreli, B. Martín-García, R. Oropesa-Nuñez, M. Prato and F. Bonaccorso, Adv. Funct. Mater., 2019, 29, 1807659.

50 S. Kwon, R. Ma, U. Kim, H. R. Choi and S. F. Baik, Carbon, 2014, 68, 118.

51 K. Zhang, H. O. Yu, Y. D. Shi, Y. F. Chen, J. B. Zeng, J. Guo, B. Wang, Z. Guo and M. Wang, J. Mater. Chem. C, 2017, 5, 2807.

52 S. Berber, Y.-K. Kwon and D. Tomanek, Phys. Rev. Lett., 2000, 84, 4613.

53 C. Yuan, B. Duan, L. Li, B. Xie, M. Huang and X. Luo, ACS Appl. Mater. Interfaces, 2015, 7, 13000.

54 Y. Zhan, J. Wu, H. Xia, N. Yan, G. Fei and G. Yuan, Macromol. Mater. Eng., 2011, 296, 590.
55 A. A. Balandin, S. Ghosh, W. Bao, I. Calizo, D. Teweldebrhan, F. Miao and C. N. Lau, Nano Lett., 2008, 8, 902.

56 G.-D. Zhan, J. D. Kuntz, A. K. Mukherjee, P. Zhu and K. Koumoto, Scr. Mater., 2006, 54, 77.

57 H. Ishida and S. Rimdusit, J. Therm. Anal. Calorim., 1999, $58,497$.

58 N. Burger, A. Laachachi, M. Ferriol, M. Lutz, V. Toniazzo and D. Ruch, Prog. Polym. Sci., 2016, 61, 1.

59 F. F. Komarov, P. Zukowski, R. M. Kryvasheyeu, E. Munoz, T. N. Koltunowicz, V. N. Rodionova and A. K. Togambaeva, Phys. Status Solidi A, 2015, 212, 425.

60 S. Sankaran, K. Deshmukh, M. B. Ahamed, K. K. Sadasivuni, M. Faisal and S. K. Khadheer Pasha, Polym. Plast. Technol. Mater., 2019, 58, 1191.

61 S. Mondal, S. Ganguly, M. Rahaman, A. Aldalbahi, T. K. Chaki, D. Khastgir and N. Ch. Das, Phys. Chem. Chem. Phys., 2016, 18, 24591.

62 L. Zhang, M. Baima and T. L. Andrew, ACS Appl. Mater. Interfaces, 2017, 9, 32299.

63 Q.-W. Wang, H.-B. Zhang, J. Liu, S. Zhao, X. Xie, L. Liu, R. Yang, N. Koratkar and Z.-Z. Yu, Adv. Funct. Mater., 2019, 29, 1806819.

64 Y. Guo, C. Dun, J. Xu, J. Mu, P. Li, L. Gu, C. Hou, C. A. Hewitt, Q. Zhang, Y. Li, D. L. Carroll and H. Wang, Small, 2017, 13, 1702645.

65 J. An and Y. G. Jeong, Eur. Polym. J., 2013, 49, 1322.

66 Y. G. Jeong and J. An, Composites, Part A, 2014, 56, 1.

67 J. Yan and Y. G. Jeong, Compos. Sci. Technol., 2015, 106, 134. 